\title{
PERANCANGAN KURSI AUTISME UNTUK MOBIL SEBAGAI ALAT BANTU TERAPI AUTISME
}

\author{
*Gostsa Khusnun Naufal, Awan Raswan, Sumar Hadi Suryo, Jamari, Ismoyo Haryanto \\ Magister Teknik Mesin, Fakultas Teknik, Universitas Diponegoro \\ Jl. Prof. Sudharto, SH., Tembalang-Semarang 50275, Telp. +62247460059 \\ *E-mail: autismemtmundip@gmail.com
}

\begin{abstract}
Children with autism tend to have hyperactivity, children will tend to be difficult to control. This is certainly an issue when children are in vehicles, especially cars. There are some events related to the automobile accident caused hyperactivity of children with autism. When the children in the car tends to move on, even disturb concentration the driver. Not many safety features on the car is intended for children with autism. Research safety equipment as well as therapeutic tools for children with autism that will be done is a autism car seat. This tool serves as an extra seat that is able to bind to safely and comfortably seat a child with autism to a primary car seat. This tool is also able to provide autism therapy with the principles of deep pressure when used, generating deep pressure with adjustable pressurized balloon. The tool is attached directly to the car seat with a harness, and then the car safety belt is used as the main security of these devices. Design tools for autism car seat through stages: preparation of product definition and technical specifications autism car seat, the design of a product concept for autism car seat, designing products for autism car seat, as well as preparation of documents for the manufacture of autism car seats.
\end{abstract}

Keywords: autism car seat,autism therapy,deep pressure,design

\section{PENDAHULUAN}

Secara umum anak autistik mengalami gangguan berbicara disamping mengalami gangguan kemampuan intelektual dan fungsi saraf serta kelainan perilaku yang ganjil dan mempunyai kehidupan sosial yang aneh serta terlihat seperti orang yang selalu sakit, tidak suka bergaul, dan sangat terisolasi dari lingkungan hidupnya. Anak autistik yang mempunyai gangguan perkembangan seperti tersebut di atas, memerlukan suatu metode terapi dan peralatan yang sifatnya khusus (berkaitan dengan pembentukan fisik, emosi, sosialisasi, dan daya nalar) [2].

Maka anak dengan kebutuhan khusus tersebut dapat disembuhkan, dengan terapi yang tepat dan dilakukan secara berkelanjutan. Terapi yang tepat dapat mengurangi bahkan dapat menghilangkan gangguan autism tersebut, sehinga anak dapat dengan normal berperilaku dan berinteraksi sosial dengan lingkungannya. Pada tahun 1990 didapat 4 anak austik dari 10.000 kelahiran $(1: 2.500)$, sedangkan pada saat ini meningkat menjadi $1: 100$, terdapat peningkatan sebesar 25 kali lipat (CDC 2001), kemudian penelitian terakhir mengungkapkan peningkatan ke arah yang lebih tinggi perbandingannya yaitu sekitar 1:88 [1].

Autisme merupakan gangguan perkembangan pada otak anak-anak yang gejalanya telah terlihat sebelum berumur tiga tahun. Autisme bukan merupakan penyakit dan tidak menular. Ada tiga perkembangan yang umumnya terganggu akibat autisme yakni : komunikasi, interaksi sosial, dan perilaku [8]. Pada anak dengan autis mereka cenderung bergerak lebih aktif dibandingkan dengan anak yang normal. Mereka tidak memperhatikan lingkungan sekitar dan lebih sibuk dengan kegiatannya sendiri. Anak dengan autis cenderung menolak kontak fisik dengan orang lain. Mereka akan melakukan penolakan dengan berbagai ekspresi mulai dari menjerit sampai dengan melakukan penolakan dengan fisik, seperti menendang, meronta, menggigit. Alat bantu terapi yang diperuntukkan untuk penderita autis sangat sedikit. Terlebih lagi alat bantu terapi yang berfungsi ganda sebagai alat terapi sekaligus sebagai alat pengaman ketika penderita autisme berada di dalam mobil yang sedang berjalan. Ketika penderita autis berada dalam mobil alat ini akan menjaga dari tindakan yang berbahaya serta melakukan terapi pada penderita pada saat yang bersamaan.

Kesulitan yang timbul jika anak dengan autis akan berpindah tempat dalam jarak yang jauh, misal bepergian menggunakan kendaraan. Sifat anak autis yang cenderung tidak bisa diam akan membahayakan dari anak tersebut serta orang lain yang berada disekitarnya. Pada saat ini fitur keselamatan pasif yang berada di mobil menggunakan sabuk pengaman. Sabuk pengaman yang digunakan dirancang untuk penggunaan normal atau dengan kata lain tidak didesain untuk penggunaan anak autis.

\subsection{Perkembangan Terapi Deep Pressure}

Sebuah penelitian yang dilakukan oleh Temple Grandin pada tahun 1965 ditemukanlah alat terapi untuk menghilangkan ketegangan (stress relieving device) atau lebih dikenal sebagai mesin pemeluk (hug machine). Prinsip dari alat ini adalah memberikan simulasi pelukan atau pemberian tekanan ke tubuh anak untuk menciptakan deep pressure yang dapat memberikan efek ketenangan [4]. Temple Grandin yang masa kecil sampai remaja pernah 
mengalami gangguan autisme, mengembangkan sebuah mesin penekan dengan sebutan "Squeeze Machine”. Dengan memberikan tekanan menadalam (deep pressure) untuk membantunya belajar mentolerir sentuhan dan mengurangi kecemasan dan kegelisahan. Squeeze machine bekerja secara lateral dan tekanan diarahkan terhadap aspek lateral seluruh tubuh, dengan menekan diantara dua dinding papan kayu yang dilapisi dengan bahan busa yang empuk [3].

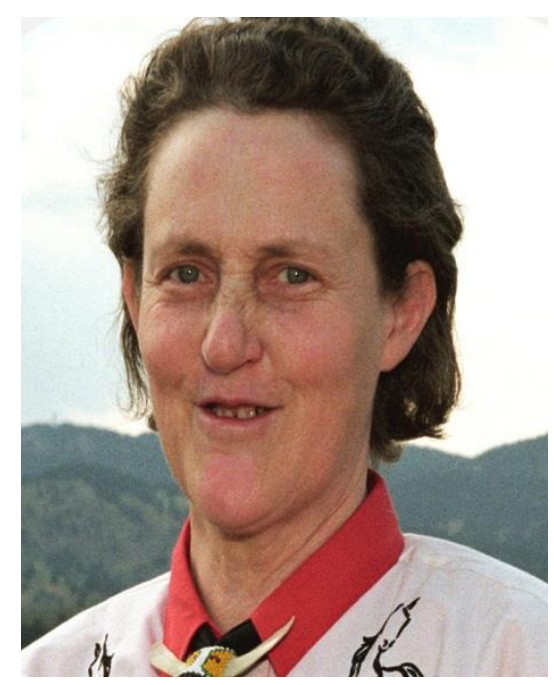

Gambar 1. Temple Grandin, Ph.D [5].

Pengamatan klinis dari beberapa penelitian menunjukkan bahwa deep pressure adalah terapi yang bermanfaat untuk anak-anak dengan gangguan autis dan mungkin anak-anak dengan gangguan attentiondeficit hyperactivity disorder (ADHD). Tercatat hanya sedikit sekali terdapat efek samping dan merupakan efek yang sangat ringan. Data hasil beberapa eksperimen menunjukkan memberikan efek menenangkan dan sebuah tinjauan literatur hewan menunjukkan bahwa hewan mengalami reaksi ketenangan yang sama [4].

Hal ini menunjukkan kemungkinan adanya efek fisiologis tambahan dari deep pressure yang diberikan oleh hug machine. Saat ini berkembang bahwa dari nilai klinis hasil pengujian, hug machine termasuk yang disarankan dapat digunakan untuk mengurangi dosis obat (psychostimulant medication). Tetapi studi klinik masih diperlukan lebih banyak lagi untuk mengevaluasi peran potensial dari stimulasi "fhysiological" [3].

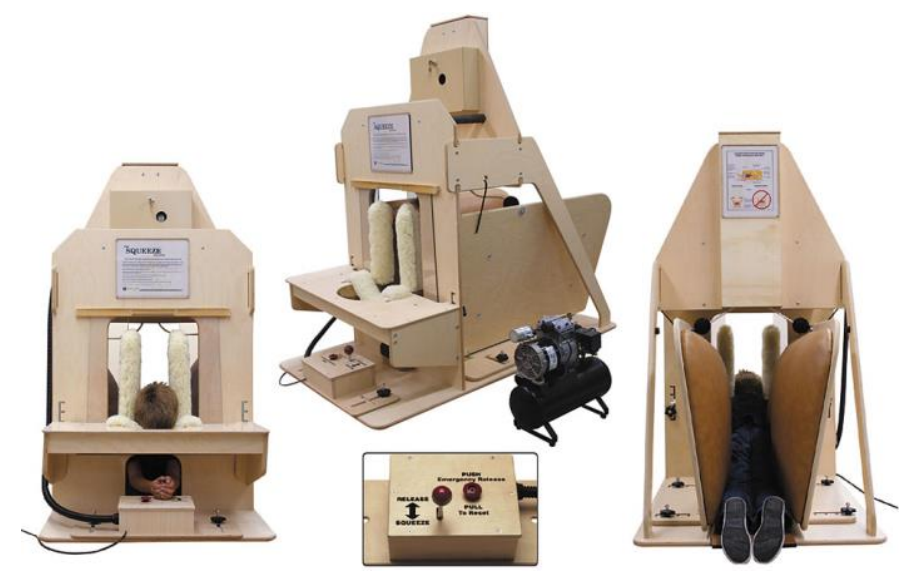

Gambar 2. Desain Hug Machine [7]. 


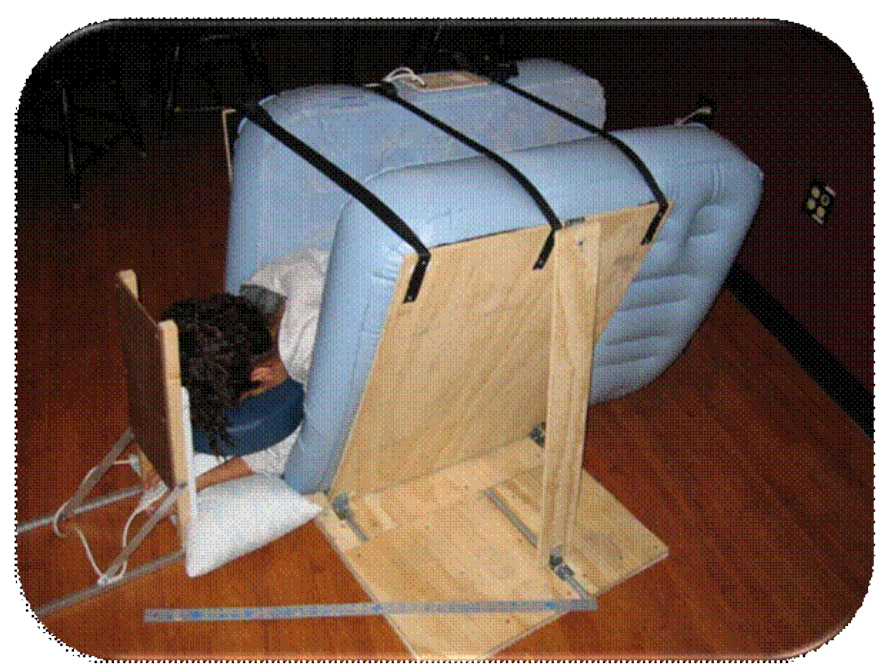

Gambar 3. Penggunaan Hug Machine [6].

\section{METODOLOGI}

Metode penelitian yang dilakukan pada perancangan kursi autisme untuk mobil adalah metode eksperimen (experimen researched method), dengan tahapan sebagai berikut:

\subsection{Studi Lapangan.}

Studi lapangan ke Yayasan Nathanisa "AGCA CENTER" Surabaya, sebagai pusat terapi penyandang autisme yang beralamat di Jalan Ngagel Jaya Tengah III/21, Surabaya. Dimana yayasan ini bergerak dalam bidang terapi anak berkebutuhan khusus salah satunya anak autis. Data awal tentang kebutuhan dari tempat terapi akan diperoleh. Serta tentang tata cara penanganan dari anak dengan autis.

\subsection{Studi Pustaka.}

Studi literatur dengan mempelajari jurnal-jurnal internasional dan buku-buku yang berkaitan dengan kursi autisme untuk mobil. Kemudian pengambilan data tambahan akan dilakukan observasi terapi di Yayasan Nathanasia "AGCA CENTER Cabang Semarang", Jalan Badak V Timur No. 50. Diharapkan dapat membantu menambah perbendaharaan pustaka penanganan terapi anak autis.

\subsection{Perancangan.}

Pada perancangan kursi autisme untuk mobil melalui beberapa tahapan antara lain:

\subsubsection{Desain Gambar}

Alat akan didesain menggunakan software desain, dengan penggunaan software ini perancangan alat dapat dilakukan secara detail dan dapat ditampilkan secara 3 dimensi. Sehingga mempermudah dalam proses selanjutnya. Dalam desain gambar ini akan dimasukkan parameter yang telah dilakukan studi sebelumnya. Mulai dari proporsi badan dari anak, kebiasaan anak serta faktor keamananan yang telah diperhitungkan sebelumnya.

\subsubsection{Pemilihan Bahan}

Pemilihan bahan dilakukan untuk membantu dalam pembangkitan deep pressure pada penggunanya. Tentunya bahan yang digunakan harus aman terhadap kulit, nyaman serta mudah dalam perawatannya. Juga diperhitungkan kemudahan dalam proses pemasangannya.

\section{HASIL dan PEMBAHASAN}

Pada perancangan kursi autisme untuk mobil akan menghasilkan beberapa dokumen, antara lain:

\subsection{Gambar Perancangan}

Alat pemeluk kursi autisme untuk mobil dirancang menggunakan bantuan software komputer, dengan bantuan software ini dapat disimulasikan bentuk akhir dari kursi autisme untuk mobil.. 


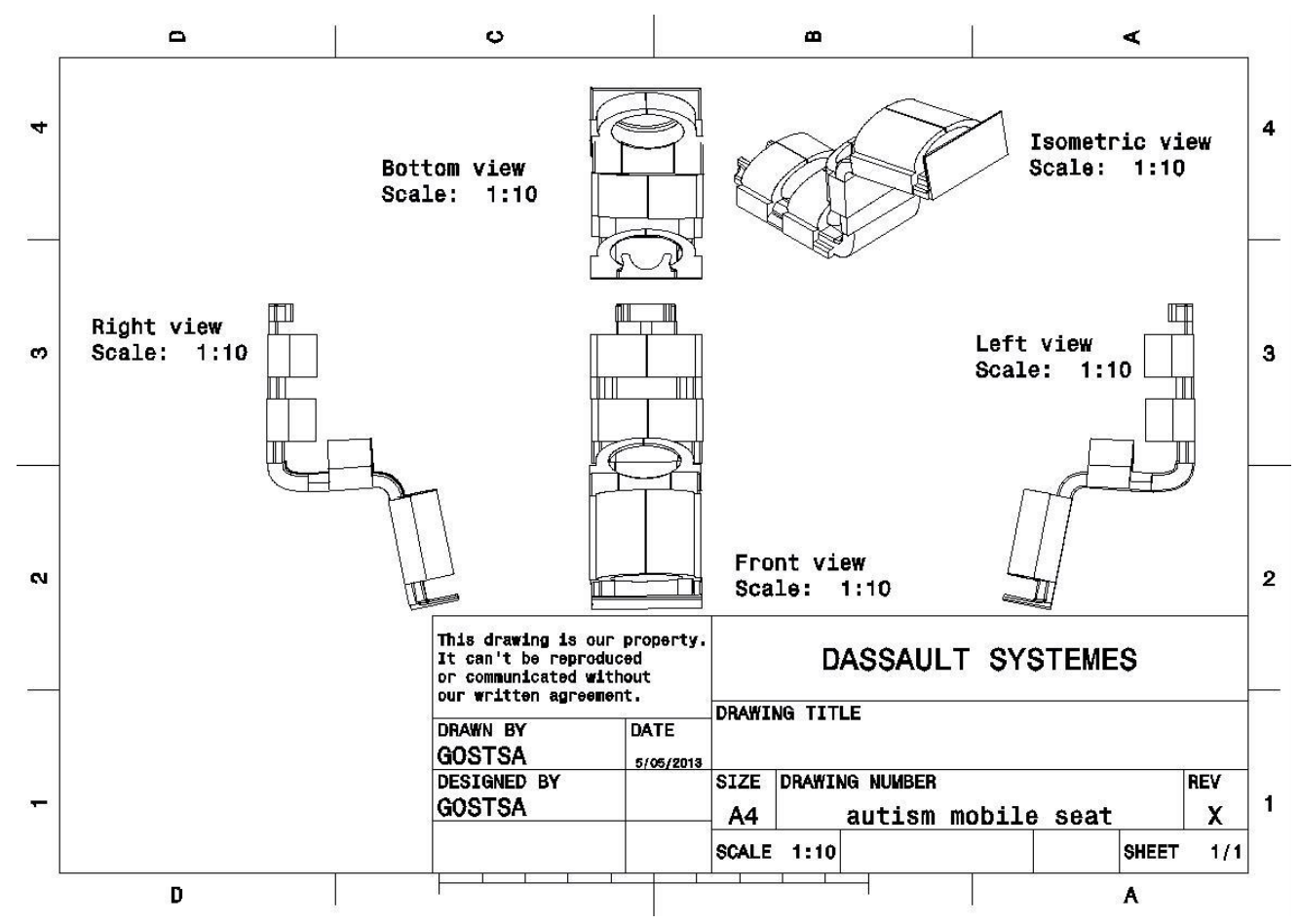

Gambar 4. Gambar teknik kursi autisme untuk mobil.

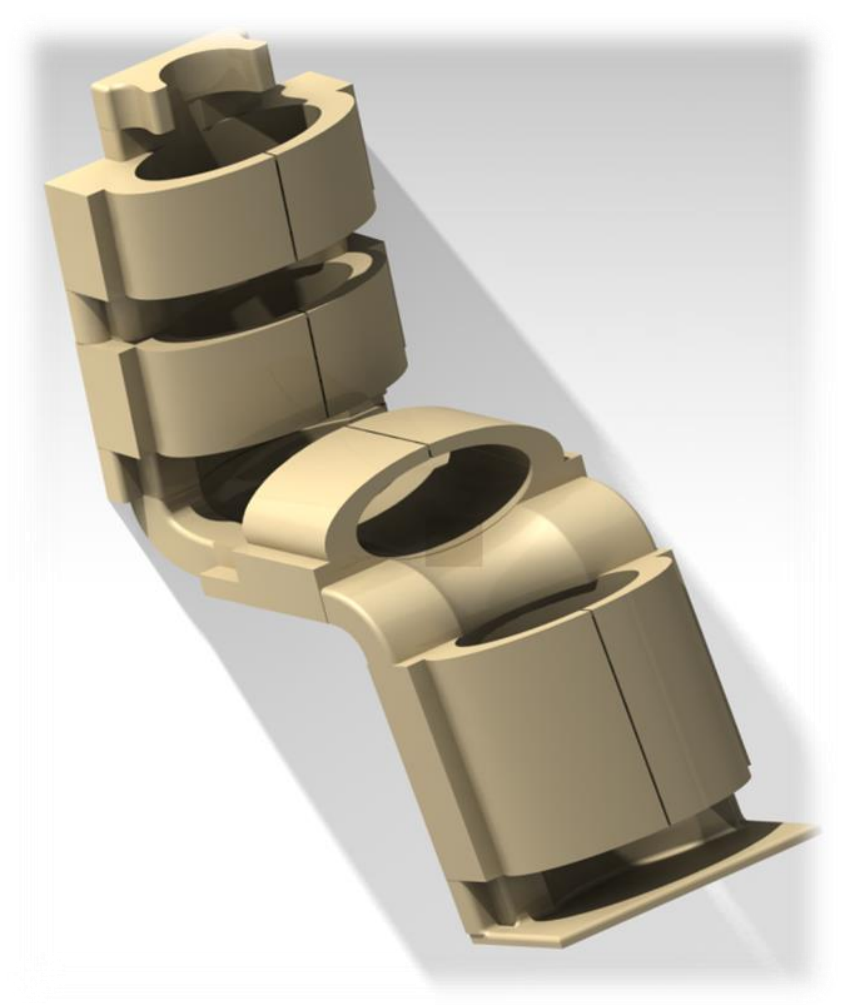

Gambar 5. Desain 3 dimensi kursi autisme untuk mobil.

\subsection{Pemilihan Bahan}

Bahan yang akan digunakan dalam kursi autisme untuk mobil terdiri dari berbagai macam bahan kain. Pada bagian dalam berupa busa yang dibentuk memanjang dengan berbagai lapisan, lapisan tersebut antara lain adalah: 


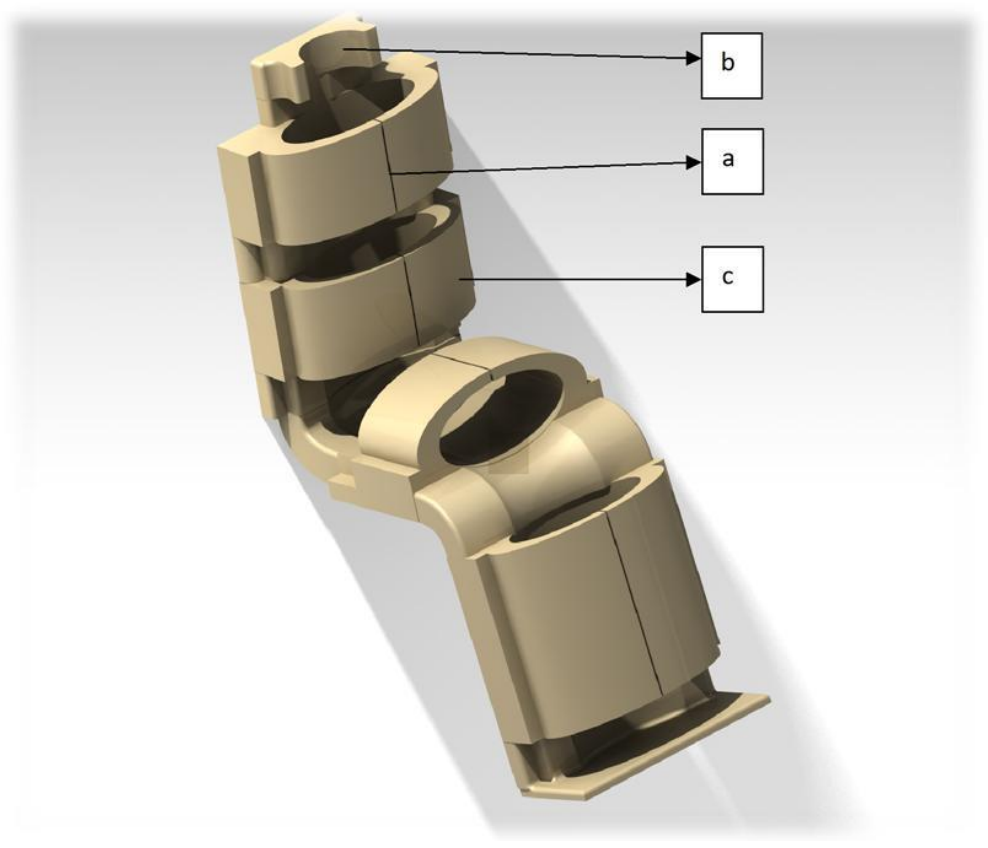

Gambar 6. Jenis bahan kursi autisme untuk mobil.

Tabel 1. Lapisan bahan kursi autisme untuk mobil.

\begin{tabular}{cl}
\hline Bagian & \multicolumn{1}{c}{ Bahan } \\
\hline $\mathrm{a}$ & Kain velkro \\
\hline $\mathrm{b}$ & Kain Dril berlapis kain perlak \\
\hline $\mathrm{c}$ & Kain katun \\
\hline
\end{tabular}

Pada bagian (a) diaplikasikan kain velkro sebagai perekat yang berfungsi sebagai pengikat ketika alat digunakan, kemudian pada bagian (b) merupakan kain dril berlapis kain perlak yang membungkus dari balon udara yang berfungsi sebagai penekan. Kemudian bagian (c) merupakan kain katun yang ditujukan sebagai penyerap keringat ketika digunakan.

\section{KESIMPULAN}

Pada fungsi sebagai alat terapi, kursi autisme untuk mobil ini menggunakan prinsip deep pressure sebagai cara untuk membantu terapi penyembuhan. Kursi autisme untuk mobil membangkitkan sensasi deep pressure dengan cara melakukan penekanan ke tubuh pengguna. Penekanan ini menggunakan balon yang berada di dalam alat, dengan balon ini alat dapat memberikan tekanan sesuai dengan keinginan dari penggunanya. Kemudian dengan menggunakan lengan pengikat yang dapat melingkar ditubuh dari pundak sampai dengan kaki. Serta menggunakan pengunci lengan pengikat dengan model push to release.

Kemudian kursi autisme untuk mobil sebagai alat pengaman ketika digunakan pada mobil, alat ini dipasangkan dengan kursi mobil, baik pada kursi depan ataupun pada kursi baris belakang. Pemasangan kursi autisme untuk mobil dengan kursi mobil menggunakan sabuk pengikat yang dapat disetel panjang pendeknya, sehingga dapat diikatkan pada berbagai macam kursi mobil. Sabuk pengikat ini melingkar pada kursi mobil baik secara horisontal maupun vertikal, tergantung dari jenis kursi mobil. Kemudian mekanisme pengunciannya menggunakan jenis push to release pada ikatan sabuk pengikat maupun pada lengan pemeluk, sehingga kursi autisme untuk mobil ketika digunakan dalam mobil ikatan pengunci tidak mudah lepas serta mencegah dari pengguna membuka ikatan pengunci lengan pemeluk dengan mudah. Kemudian pada bagian belakang kursi autisme untuk mobil terdapat rangka yang dapat disetel. Sehingga kursi autisme untuk mobil dapat digunakan dalam posisi terlentang ataupun posisi duduk. Pada rangka ini juga sebagai penguat ketika kursi autisme untuk mobil dipasangkan dengan kursi pada mobil. Ketika mobil dalam keadaan melaju ataupun mengerem posisi kursi autisme untuk mobil tidak akan bergeser, terikat kuat dengan kursi mobil.

\section{REFERENSI}

[1] CDC-Autism Spectrum Disorder (ASDs)-NCBDDD www.cdc.gov/ncbddd/autism/index.html Diakses: 4/8/2013 9:19 PM

[2] Delphie, Bandi, Prof., Dr. MA., SE.(2012). Pembelajaran Anak Tunagrahita, Suatu Pengantar dalam Pendidikan Inklusi, Cetakan kedua, PT. Refika Aditama, Bandung 
[3] Grandin, Temple, Ph.D., Scariano, MM. (1986). Emergence: Labeled Autistic, p. 91. Warner Books, Departemen of Animal Science, Colorado State Univercity, Fort Collins, CO 80526, Novato, CA, Arena Press, USA.

[4] Grandin, Temple, Ph.D. (1992). Calming Effects of Deep Touch Pressure in Patients with Autistic Disorder, College Students, and Animals, Journal of Child and Adolescent Psychopharmacology, Volume 2, Number 1, Mary Ann Liebert, Inc., Publishers.

[5] http://www.autismconferencesofamerica.com/ (Diakses: 15 Oktober 2012 jam !5:30).

[6] http:// www.hugmachine.org/ (Diakses: 18 Oktober 2012 jam 17:20).

[7] http://www.therafin.com/squeezemachine.htm (Diakses: 15 Oktober 2012 jam !5:30).

[8] Handoyo, Yakub, Dr. dr., MPH.(2003). Autisma: Petunjuk Praktis dan Pedoman Materi untuk Mengajar Anak Normal, Autis dan Perilaku Lain, Cetakan kedua, PT. Bhuana Ilmu Populer, Jakarta. 